\title{
Advances in the imaging of pituitary tumours
}

AUTHOR NAMES AND DEGREES

*James MacFarlane MRCP(UK)1, *Waiel A Bashari MSc MRCP(UK $)^{1}$, *Russell Senanayake MSc MRCP $(U K)^{1}$, Daniel Gillett MSc ${ }^{1,2}$, Merel van der Meulen BSc $^{1}$, Andrew S Powlson MRCP $(U K)^{1}$, Angelos Kolias PhD FRCS ${ }^{1,3}$, Olympia Koulouri PhD MRCP(UK $)^{1}$, Mark Gurnell PhD FRCP ${ }^{1}$

* These authors contributed equally to this work.

\section{AUTHOR AFFILIATIONS}

${ }^{1}$ Cambridge Endocrine Molecular Imaging Group, Metabolic Research Laboratories, Wellcome TrustMRC Institute of Metabolic Science, University of Cambridge, and National Institute for Health Research, Cambridge Biomedical Research Centre, Addenbrooke's Hospital, Hills Road, Cambridge, CB2 OQQ, UK

${ }^{2}$ Department of Nuclear Medicine, Addenbrooke's Hospital, Hills Road, Cambridge, CB2 OQQ, UK ${ }^{3}$ Department of Neurosurgery, Addenbrooke's Hospital, Hills Road, Cambridge, CB2 OQQ, UK

\section{CORRESPONDING AUTHOR}

Professor Mark Gurnell, Metabolic Research Laboratories, Wellcome Trust-MRC Institute of Metabolic Science, University of Cambridge, Box 289, Addenbrooke's Hospital, Hills Road, Cambridge CB2 0QQ, UK.

Tel: +44-1223-348739

E-mail: mg299@medschl.cam.ac.uk

\section{DISCLOSURE STATEMENT}

The Authors have nothing to disclose.

Funding sources: JM, WB, RS, DG, AK, OK and MG are supported by the Cambridge NIHR Biomedical Research Centre; this work was also supported by a project grant from the Evelyn Trust (WB, OK, MG).

\section{KEY WORDS}

Pituitary adenoma, MRI, PET/CT, ${ }^{11} \mathrm{C}$-methionine, Met-PET/MR ${ }^{\mathrm{CR}}$

\section{KEY POINTS}

- MRI remains the primary modality for imaging pituitary tumours (pituitary adenomas, PA) 
- Conventional MR sequences provide sufficient information to guide management in the majority of patients, but can lack sensitivity and specificity for: (i) detection of microadenomas; (ii) identification of the site(s) of residual/recurrent disease following primary therapy

- Alternative MR sequences may aid characterisation of specific tumour traits (e.g. tumoral consistency; presence of apoplexy; invasion of surrounding structures)

- Several different radiotracers have been investigated for molecular imaging of pituitary tumours with varying success

- 11C-methionine PET co-registered with volumetric (1 mm slice) MRI (Met-PET/MR ${ }^{\mathrm{CR}}$ ) can:

- aid accurate localisation of micro/pico-adenomas of all PA subtypes

- identify sites of recurrent or incompletely resected disease and distinguish from post-operative change (e.g. acromegaly, Cushing's disease)

- augment radiotherapy planning in selected cases

\section{SYNOPSIS}

In most patients with pituitary adenomas (PA) magnetic resonance imaging (MRI) is essential to guide effective decision-making. A combination of T1- ( \pm gadolinium enhanced) and T2-weighted sequences are commonly employed and allow the location and extent of the adenoma to be determined. In some instances, supplementary MR sequences (e.g. diffusion weighted; FLAIR; MR angiography; MR elastography) may provide additional information to guide surgery. However, in an important subgroup of patients MRI findings are 'negative' or equivocal (e.g. with failure to reliably identify the site of a microadenoma or to distinguish postoperative change from residual/recurrent disease). In this setting, molecular (functional) imaging [e.g. ${ }^{11} \mathrm{C}$-methionine PET/CT coregistered with volumetric MRI (Met$\left.\mathrm{PET} / \mathrm{MR}^{\mathrm{CR}}\right)$ ] may allow accurate localisation of the site of de novo or persistent disease to guide definitive treatment (e.g. surgery or radiosurgery).

Word count (including references and figure legends): 6939 words 


\section{INTRODUCTION}

Pituitary adenomas (PA) are typically benign, slow-growing tumours of the adenohypophysis, which come to attention due to associated endocrine dysfunction (e.g. hyperprolactinaemia, hypercortisolism, acromegaly/gigantism, hypopituitarism) and/or mass effect (e.g. compression of the optic chiasm or cranial nerves in the wall of the cavernous sinus), or when they are discovered incidentally during crosssectional imaging of the brain performed for a separate indication ${ }^{1}$.

Pituitary incidentalomas are a relatively common finding in the general population, with a large metaanalysis of autopsy series suggesting a mean prevalence of $10.7 \%$ (range $1.5-31 \%)^{2}$. These findings are broadly consistent with magnetic resonance imaging (MRI) studies of the sella and parasellar regions, which identify abnormalities in as many as $10-38 \%$ of subjects in unselected cohorts ${ }^{3,4}$. The majority of these are microadenomas and most do not result in endocrine dysfunction ${ }^{5}$. In contrast, clinically relevant PA have been estimated to affect between 1:1064 and 1:1200 of the general population ${ }^{6,7}$.

Modern management of pituitary adenomas is ideally overseen by a specialist multidisciplinary team comprising neuroendocrinology, neurosurgery/otolaryngology, neuroradiology, neuropathology, neuroophthalmology and neuro-oncology ${ }^{8}$. Cross-sectional imaging [MRI and/or computed tomography (CT)] of the sella and parasellar regions is central to effective decision-making and may be the major determinant of whether a patient is offered surgery, radiotherapy, medical therapy or surveillance. For the majority of cases, MRI remains the primary imaging modality and distinguishes the adenoma from normal pituitary tissue and adjacent structures ${ }^{9,10}$. However, in a small but important subgroup of patients conventional pituitary imaging is not informative. For example, whilst incidentalomas are a common finding in the general population, paradoxically some functioning microadenomas (including $30-40 \%$ of corticotroph adenomas) are not readily visualised on standard pituitary MR sequences ${ }^{11}$. Similarly, following transsphenoidal surgery (TSS), site(s) of residual or recurrent disease may not be evident or readily distinguished from post-treatment changes ${ }^{12}$. In these contexts, the decision then lies between 'blind' surgical (re-)exploration, long-term (in some cases life-long) medical therapy, radiotherapy or even a combination of approaches, each with their own limitations with respect to the likelihood and time to achieving disease control, risk of inducing hypopituitarism, and causation of other adverse effects.

Accordingly, several novel approaches to pituitary imaging have been proposed, largely based around the deployment of alternative MR sequences and/or novel techniques for image analysis, with the aims of: (i) improving diagnostic resolution, (ii) informing pre-treatment planning and (iii) predicting likely responses to different therapeutic strategies. In addition, a role for molecular imaging, with its ability to confirm/localise sites of functioning active tumour, is gaining prominence and may be particularly valuable when cross-sectional imaging remains equivocal. Here, we consider how these advances 
might be integrated into modern imaging algorithms to better inform the management of patients with pituitary adenomas.

\section{MAGNETIC RESONANCE IMAGING}

In a patient in whom a pituitary adenoma (PA) is suspected, dedicated MRI of the sella and parasellar regions should be performed to confirm the site and size of the tumour and its relationship to surrounding important structures. CT may offer important supplementary information in some cases (e.g. defining the extent of bony erosion with larger tumours; confirming/excluding the presence of calcification), and modern thin slice CT is a reasonable alternative for those unable or unwilling to undergo $\mathrm{MRI}^{10}$.

\section{Standard clinical pituitary MRI}

Spin-echo (SE) pulse sequences are one of the earliest developed and still widely used of all MRI pulse sequences, and remain a cornerstone of modern pituitary imaging. Although practice varies from centre to centre, routine clinical pituitary MRI protocols [using a 1.5 Tesla (1.5T) or 3T scanner] typically include:

- pre-contrast T1-weighted SE and T2-weighted fast SE (FSE) coronal and sagittal sections with thin slices (typically 2-3 $\mathrm{mm}$ )

- $\quad$ post-contrast T1-weighted SE coronal and sagittal sections with thin slices

The addition of axial images may also be helpful in some cases and allows for more complete evaluation of the posterior pituitary gland ${ }^{13}$.

The normal anterior pituitary gland is isointense to grey matter on non-contrast T1- and T2-weighted SE/FSE sequences; the posterior lobe demonstrates high T1 signal, but is hypointense on T2. Following injection of contrast, the infundibulum and gland progressively enhance (homogeneously). Contrast uptake by pituitary adenomas is typically slower, resulting in delayed enhancement and washout ${ }^{10,14}$.

For cases without a clear abnormality on MRI, but in whom a lesion is strongly suspected on clinical grounds (e.g. ACTH-dependent Cushing's syndrome with biochemical and/or petrosal sinus catheter evidence of a central origin), dynamic contrast-enhanced MRI (using T1-weighted sequences pre- and immediately post-contrast administration) may help identify the site of a microadenoma. However, gradient echo [e.g. spoiled gradient echo (SGE), (fast) spoiled gradient recalled echo (FSPGR/SPGR)], which allows imaging with a $1 \mathrm{~mm}$ slice interval, has been suggested to offer greater sensitivity for localising microadenomas in the context of Cushing's disease ${ }^{15,16}$.

The most commonly employed contrast agent for pituitary imaging is gadolinium, a naturally-occurring lanthanide with strong paramagnetic properties (due to seven unpaired electrons). In its free form gadolinium is toxic and must therefore be chelated to a carrier ligand to permit safe clinical use. Recently 
however, concern has arisen regarding the potential for gadolinium deposition in the central nervous system even in patients with normal renal function ${ }^{17,18}$, which presents a particular challenge for pituitary endocrinologists and their patients given the often long-term requirement for periodic surveillance imaging ${ }^{19}$. It is therefore important that the need for contrast enhancement is carefully considered whenever imaging of the sella and parasellar regions is requested. For example, in a patient with a well-defined intrasellar tumour remnant following primary surgery for a non-functioning PA, and which is well visualised on non-contrast MRI, the inclusion of post-gadolinium sequences is likely to add little to the clinical decision making process - if there are concerns regarding tumour enlargement on noncontrast T1- and T2-weighted images the patient can be recalled for further assessment.

Similarly, attention has recently been drawn to those clinical settings in which T2-weighted MRI can afford comparable or even superior information to that provided by T1-weighted post-contrast imaging ${ }^{20}$, thus potentially avoiding the need for initial and/or repeat gadolinium administration (Table 1) (Figure 1).

\section{Insert Table 1 and Figure 1 here}

\section{Alternative pituitary MR sequences/techniques}

An increasing array of MR sequences have been adapted for use in pituitary disease. In addition, as the availability of higher field strength MRI systems (e.g. 7T) increases, potential applications in patients with PA are being increasingly explored. Currently, most of these approaches remain outside standard clinical protocols for imaging of the sella and parasellar regions, but may be requested when conventional sequencies leave important questions unanswered. These can be broadly considered under three categories (Table 2).
A) As an aid to diagnosis
B) To help inform preoperative assessment
C) To predict likely treatment outcomes.

\section{Insert Table 2 here}

\section{Advances in image analysis}

Novel approaches to image analysis are also being translated from other disease areas, allowing additional information to be derived from existing pituitary MR protocols. For example, in a study of 89 patients who had undergone transsphenoidal surgery (TSS), and for whom the tumour Ki-67 proliferation index was available, machine learning analysis of texture-derived parameters from preoperative T2-weighted MRI allowed prediction of which tumours would exhibit a high Ki-67 labelling index ${ }^{21}$. The adoption of a machine learning approach to the analysis of T2-weighted MRI has also been proposed as a means of evaluating macroadenoma consistency (and hence potential ease of resection) prior to surgery ${ }^{22}$. If substantiated in larger studies, wider roll-out of automated image 
analysis techniques could enable a more personalised approach to initial management and follow-up, using protocols for image acquisition that are already well established in most centres.

\section{MOLECULAR (FUNCTIONAL) IMAGING}

Molecular (functional) imaging is an important facet of the diagnostic pathway for several endocrine disorders: e.g. technetium 99m ( ${ }^{99 \mathrm{~m} T c}$ )-pertechnetate scintigraphy in hyperthyroidism; ${ }^{99 \mathrm{~m} T c-s e s t a m i b i}$ scintigraphy/single photon emission computed tomography (SPECT) in hyperparathyroidism; Indium$111\left({ }^{111} \mathrm{In}\right)$-pentetreotide scintigraphy/SPECT or Gallium-68 $\left({ }^{68} \mathrm{Ga}\right)$-DOTATATE positron emission tomography (PET)/CT in neuroendocrine tumours (NETs). In addition to identifying the cause / localising sites of abnormal functioning tissue, in some instances it can also inform treatment decisions [e.g. use of Lutetium-177 ( ${ }^{177} \mathrm{Lu}$ )-DOTATATE therapy in patients with metastatic NETs].

In contrast, molecular imaging has not traditionally been considered part of the diagnostic armamentarium for de novo or recurrent pituitary adenomas. Although several groups have explored tracers targeting different cellular pathways and receptor expression, the limitations associated with imaging the sella and parasellar regions using scintigraphy or CT have proved a significant challenge for both accurate PA localisation and discrimination of tumour from remaining normal pituitary tissue. However, several recent advances, including coregistration of high resolution PET-CT with volumetric (1 mm slice) MRI (PET/MR ${ }^{C R}$ ) and the advent of PET/MR scanners, have allowed for more accurate localisation of the site(s) of tracer uptake and differentiation from physiological uptake by the remaining normal pituitary gland.

\section{Somatostatin receptor imaging}

Earlier attempts at imaging pituitary adenomas using tracers targeting somatostatin receptors faltered on several counts, including the relatively poor spatial resolution of scintigraphy (even when combined with SPECT), variable somatostatin receptor (SSTR) expression of individual tumours, and competing background uptake by normal pituitary tissue. More latterly, studies using ${ }^{68} \mathrm{Ga}$-DOTATATE and ${ }^{68} \mathrm{Ga}-$ DOTATOC have shown greater promise, benefiting from the significantly improved spatial resolution offered by PET. Intriguingly, in one study lower tracer uptake was observed in clinically non-functioning PA (7 SF-1 and 2 T-Pit staining tumours) when compared with normal pituitary gland ${ }^{23}$. Moreover, comparing and contrasting appearances from ${ }^{68} \mathrm{Ga}$-DOTATATE PET with those of ${ }^{18} \mathrm{~F}$ fluorodeoxyglucose $\left({ }^{18} \mathrm{~F}-\mathrm{FDG}\right)$-PET has been proposed as a means of differentiating recurrent/residual pituitary adenoma from normal pituitary tissue ${ }^{24,25}$, and may also inform decision-making for aggressive pituitary tumours 26,27 .

\section{Dopamine receptor imaging}

Prolactin secretion from normal lactotrophs is subject to tonic dopaminergic inhibition, which is predominantly mediated by the dopamine receptor subtype $2(\mathrm{D} 2 \mathrm{R}){ }^{28}$. Although several high-affinity 
ligands for the D2 receptor, which have been used for PET imaging in other clinical contexts (e.g. psychiatric disorders), have been deployed for imaging $\mathrm{PA}^{29,30}$, to date they have failed to find a role in routine pituitary practice. In part, this likely reflects the relatively limited utility of functional imaging in tumours which are predominantly managed medically, with a high expectation of dopamine agonist sensitivity. In contrast, in acromegaly, where only approximately one in four somatotroph adenomas respond to dopamine agonist therapy, a functional imaging modality capable of predicting response to treatment (as reflected by focal PET tracer uptake) could represent a useful addition to the diagnostic algorithm when considering which patients might benefit from a trial of dopamine agonist for persistent residual disease.

\section{Fluorine-18 $\left({ }^{18} \mathrm{~F}\right)-\mathrm{FDG}$ PET}

${ }^{18} \mathrm{~F}$-fluorodeoxyglucose $\left({ }^{18} \mathrm{~F}-\mathrm{FDG}\right)$ is a well-established PET tracer which finds widespread use in clinical oncology. Importantly, in a large retrospective study, which assessed pituitary uptake in 40,967 subjects undergoing ${ }^{18} \mathrm{~F}$-FDG PET/CT for other indications, focal increased tracer uptake in the pituitary fossa was observed in just $0.073 \%$ of cases, several of whom were subsequently shown to have pituitary adenomas ${ }^{31}$; in a second study with a smaller sample size (13,145 subjects), incidental pituitary uptake was noted in $0.8 \%$ of subjects, although a significant proportion of these were not confirmed to represent pathological uptake on subsequent assessment ${ }^{32}$. Together, these studies point to a likely low risk of false positive scans $(<1 \%)$ and highlight the importance of referral for endocrine assessment in any patient with incidentally detected pituitary ${ }^{18} \mathrm{~F}-\mathrm{FDG}$ uptake. In keeping with this, the literature contains numerous examples of different pituitary adenoma subtypes discovered incidentally during ${ }^{18} \mathrm{~F}-\mathrm{FDG} \mathrm{PET} / \mathrm{CT}$ [non-functioning $\mathrm{PA}^{33,3435}$, prolactinoma ${ }^{36}$, gonadotropinoma ${ }^{37}$, somatotropinoma ${ }^{38,39}$ and corticotropinoma ${ }^{40}$ ].

A role for ${ }^{18} \mathrm{~F}$-FDG PET in the detection of de novo and residual/recurrent PA has been explored by several groups. In a prospective study of 24 patients with different subtypes of PA, all macroadenomas $(n=14)$ and half of microadenomas $(n=5)$ demonstrated increased tracer uptake ${ }^{41}$. As outlined previously, ${ }^{18} \mathrm{~F}$-FDG PET may also help distinguish residual or recurrent adenoma from remaining normal pituitary tissue following transsphenoidal surgery when combined with ${ }^{68} \mathrm{Ga}$-DOTATATE PET 24.

However, perhaps the greatest interest in the application of ${ }^{18}$ FDG PET in the management of pituitary disease has been in the field of Cushing's disease, where $30-40 \%$ of microadenomas may go unidentified on standard clinical MRI. In a study of 12 patients with pituitary Cushing's ${ }^{18}$ F-FDG PET was found to be comparable to MRI for the localisation of corticotroph adenomas with a detection rate of approximately $60 \%$, albeit without complete overlap between the two imaging modalities ${ }^{42}$. In a prospective study of 10 patients with Cushing's disease, Chittiboina and colleagues were able to show 
slight superiority of ${ }^{18} \mathrm{~F}$-FDG PET in comparison with conventional spin-echo (SE) MRI but, in the same cohort, spoiled gradient recalled echo (SPGR) MRI was superior to ${ }^{18}$ FDG PET ${ }^{43}$. However, more recently the same group has shown that prior stimulation with corticotropin-releasing hormone $(\mathrm{CRH})$ may enhance the ability of ${ }^{18}$ F-FDG PET to detect corticotropinomas ${ }^{44}$.

\title{
Nitrogen-13 $\left({ }^{13} \mathrm{~N}\right)$-Ammonia PET
}

\begin{abstract}
${ }^{13} \mathrm{~N}$-ammonia has previously been proposed as a marker of pituitary gland perfusion and metabolism, which allows the localisation of normal functioning tissue, with reduced/absent uptake following pituitary injury ${ }^{45}$. Perhaps mirroring this, in a single study of ${ }^{13} \mathrm{~N}$-ammonia PET/CT in 48 patients with different PA subtypes (22 NFPA, 12 acromegaly, 10 Cushing's disease, four prolactinomas), higher tracer uptake was observed in normal residual pituitary tissue compared to adenoma (which contrasted with findings on ${ }^{18} \mathrm{~F}$-FDG PET/CT) ${ }^{46}$. However, the ability of ${ }^{13} \mathrm{~N}$-ammonia PET/CT to identify the site of normal pituitary tissue was diminished when the maximal tumour diameter exceeded $2 \mathrm{~cm}^{46}$.
\end{abstract}

\section{Fluorine-18 $\left({ }^{18} \mathrm{~F}\right)$-Choline}

${ }^{18} \mathrm{~F}$-Choline, a PET tracer employed in the staging and re-staging of prostate cancer, is taken up by the normal pituitary gland ${ }^{47,48}$, raising the possibility of a role in imaging pituitary adenomas. However, to date, support for such a role is limited to a small number of case reports of incidentally detected pituitary macroadenomas ${ }^{49,50}$. It is also unclear whether uptake in pituitary adenomas is dependent on cellular proliferation (with incorporation into cell membranes), or reflects other aspects of choline transport/metabolism, as has been proposed for other well-differentiated endocrine tumours ${ }^{51}$.

\section{Carbon-11 ( $\left.{ }^{11} \mathrm{C}\right)$-methionine}

The hallmark of pituitary adenomas is inappropriate peptide synthesis, even in clinically non-functioning tumours of the gonadotrope (SF-1) lineage. Accordingly, molecular imaging using a labelled amino acid PET tracer has the immediate attraction of potentially finding application in all PA subtypes. To date, the most studied amino acid tracer in PA is ${ }^{11} \mathrm{C}$-methionine, which benefits from considerably lower brain uptake (producing a more favourable target-to-background ratio), and increased sensitivity for the detection of PA, when compared with ${ }^{18} \mathrm{~F}-\mathrm{FDG}{ }^{52-54}$.

Perhaps the single most important recent advance in pituitary imaging using ${ }^{11} \mathrm{C}$-methionine has been the move to routine co-registration of PET/CT and MRI images (Met-PET/MRICR), which allows (i) more accurate (anatomical) localisation of the site(s) of methionine uptake, and (ii) more reliable distinction between tumoral and normal pituitary tissue tracer uptake ${ }^{12,54-56}$; the advent of PET/MR hybrid scanners will likely further capitalise on these advances. 
As with other functional imaging modalities, biochemical assessment of disease status should be performed on the day of the ${ }^{11} \mathrm{C}$-methionine scan. In addition, patients treated with agents that suppress tumour function require a period of medication washout prior to imaging (e.g. 3 months for SSA therapy; 4 weeks for DA therapy).

Currently, there are two main clinical scenarios when Met-PET/MRI ${ }^{C R}$ should be considered:

A) In de novo pituitary disease when targeted intervention (e.g. transsphenoidal surgery or stereotactic radiosurgery) is being considered, but MRI is either 'negative' or equivocal

B) In patients with persistent/recurrent disease following previous intervention (surgery \pm radiotherapy/radiosurgery \pm medical therapy), when further targeted intervention would be considered but MRI is unable to reliably identify the site(s) of residual/recurrent disease and/or distinguish from post-treatment change.

Patients in group A include up to $30 \%$ of patients with Cushing's disease (Figure 2), occasional patients with acromegaly due to an occult microadenoma (Figure 3), some thyrotropinomas, and a small group of prolactinomas with dopamine agonist resistance and/or intolerance ${ }^{57,58}$.

\section{Insert Figures 2 and 3 here}

While all PA subtypes may be represented in group B, persistence/recurrence of hypercortisolism or acromegaly are the most common reasons for referral to our centre for Met-PET/MRICR (Figures 4 \& $5)^{12,57}$. Importantly, a significant proportion of patients with acromegaly who were previously deemed unsuitable for further surgical intervention can be offered a second or even third transsphenoidal approach following Met-PET/MRI ${ }^{C R}$ with the expectation of achieving full remission or a significant improvement in disease control ${ }^{12}$. More recently, we have also shown that subjects with suspected lateral sellar/parasellar disease may derive particular benefits from such an approach (Bashari et al, 2020 , in press).

\section{Insert Figures 4 and 5 here}

\section{SUMMARYIDISCUSSION}

For the majority of patients diagnosed with a pituitary adenoma, good quality T1- ( \pm contrast enhancement) and T2-weighted MRI sequences will provide all of the information that is required to facilitate effective and timely decision-making. However, imaging of pituitary tumours is an evolving field, both in response to, and as a driver of, developments in surgical, radiotherapeutic and 
pharmacological management strategies. Increasing use of alternative MR sequences may aid localisation of small functional tumours. Advances in analysis of MRI characteristics have the potential to predict tumour type and response to medical treatment. Molecular (functional) imaging, most clearly demonstrated to date with ${ }^{11} \mathrm{C}$-methionine PET (Met-PET/MR ${ }^{\mathrm{CR}}$ ), is potentially able to facilitate curative surgery/radiotherapy (with minimum disruption of normal pituitary function) in an increasing number of scenarios, in both de novo and residual/recurrent pituitary disease. Molecular imaging may also be an aid in predicting response to specific medical therapies. In an era of personalised, precision medicine, imaging has an important, and increasing role in decision-making in pituitary disease. 


\section{References}

1. $\quad$ Melmed S. Pituitary-Tumor Endocrinopathies. Longo DL, ed. $N$ Engl J Med. 2020;382(10):937-950. doi:10.1056/NEJMra1810772

2. Molitch ME. Pituitary incidentalomas. Best Pract Res Clin Endocrinol Metab. 2009;23(5):667-675. doi:10.1016/j.beem.2009.05.001

3. Hall WA. Pituitary Magnetic Resonance Imaging in Normal Human Volunteers: Occult Adenomas in the General Population. Ann Intern Med. 1994;120(10):817. doi:10.7326/0003-4819-120-10-19940515000001

4. Chong BW, Kucharczyk W, Singer W, George S. Pituitary gland MR: A comparative study of healthy volunteers and patients with microadenomas. Am $J$ Neuroradiol. 1994;15(4):675-679. http://www.ncbi.nlm.nih.gov/pubmed/8010269.

5. Vasilev V, Rostomyan L, Daly AF, et al. Pituitary "incidentaloma": Neuroradiological assessment and differential diagnosis. Eur J Endocrinol. 2016;175(4):R171-R184. doi:10.1530/EJE-15-1272

6. Daly AF, Rixhon M, Adam C, Dempegioti A, Tichomirowa MA, Beckers A. High prevalence of pituitary adenomas: A cross-sectional study in the province of Liège, Belgium. $J$ Clin Endocrinol Metab. 2006;91(12):4769-4775. doi:10.1210/jc.2006-1668

7. Fernandez A, Karavitaki N, Wass JAH. Prevalence of pituitary adenomas: A community-based, crosssectional study in Banbury (Oxfordshire, UK). Clin Endocrinol (Oxf). 2010. doi:10.1111/j.13652265.2009.03667.x

8. Casanueva FF, Barkan AL, Buchfelder M, et al. Criteria for the definition of Pituitary Tumor Centers of Excellence (PTCOE): A Pituitary Society Statement. Pituitary. 2017;20(5):489-498. doi:10.1007/s11102017-0838-2

9. Pressman BD. Pituitary Imaging. Endocrinol Metab Clin North Am. 2017;46(3):713-740. doi:10.1016/j.ecl.2017.04.012

10. Bashari WA, Senanayake R, Fernández-Pombo A, et al. Modern imaging of pituitary adenomas. Best Pract Res Clin Endocrinol Metab. 2019;33(2):101278. doi:10.1016/j.beem.2019.05.002

11. Erickson D, Erickson B, Watson R, et al. 3 Tesla magnetic resonance imaging with and without corticotropin releasing hormone stimulation for the detection of microadenomas in Cushing's syndrome. Clin Endocrinol (Oxf). 2010;72(6):793-799. doi:10.1111/j.1365-2265.2009.03723.x

12. Koulouri O, Kandasamy N, Hoole AC, et al. Successful treatment of residual pituitary adenoma in 
persistent acromegaly following localisation by 11C-methionine PET co-registered with MRI. Eur J Endocrinol. 2016;175(5):485-498. doi:10.1530/EJE-16-0639

13. Bonneville J-F. Magnetic Resonance Imaging of Pituitary Tumors. Front Horm Res. 2016;45:97-120. doi:10.1159/000442327

14. Bonneville JF, Bonneville F, Cattin F. Magnetic resonance imaging of pituitary adenomas. Eur Radiol. 2005;15(3):543-548. doi:10.1007/s00330-004-2531-x

15. Kasaliwal R, Sankhe SS, Lila AR, et al. Volume interpolated 3D-spoiled gradient echo sequence is better than dynamic contrast spin echo sequence for MRI detection of corticotropin secreting pituitary microadenomas. Clin Endocrinol (Oxf). 2013;78(6):825-830. doi:10.1111/cen.12069

16. Grober Y, Grober H, Wintermark M, Jane JA, Oldfield EH. Comparison of MRI techniques for detecting microadenomas in Cushing's disease. J Neurosurg. 2018;128(4):1051-1057. doi:10.3171/2017.3.jns163122

17. McDonald RJ, McDonald JS, Kallmes DF, et al. Gadolinium deposition in human brain tissues after contrast-enhanced MR imaging in adult patients without intracranial abnormalities. Radiology. 2017;285(2):546-554. doi:10.1148/radiol.2017161595

18. Bussi S, Coppo A, Botteron C, et al. Differences in gadolinium retention after repeated injections of macrocyclic MR contrast agents to rats. J Magn Reson Imaging. 2018;47(3):746-752. doi:10.1002/jmri.25822

19. Nachtigall LB, Karavitaki N, Kiseljak-Vassiliades K, et al. Physicians' awareness of gadolinium retention and MRI timing practices in the longitudinal management of pituitary tumors: a "Pituitary Society" survey. Pituitary. 2019;22(1):37-45. doi:10.1007/s11102-018-0924-0

20. Bonneville J-F. A plea for the T2W MR sequence for pituitary imaging. Pituitary. 2019;22(2):195-197. doi:10.1007/s11102-018-0928-9

21. Ugga L, Cuocolo R, Solari D, et al. Prediction of high proliferative index in pituitary macroadenomas using MRI-based radiomics and machine learning. Neuroradiology. 2019;61(12):1365-1373. doi:10.1007/s00234-019-02266-1

22. Zeynalova A, Kocak B, Durmaz ES, et al. Preoperative evaluation of tumour consistency in pituitary macroadenomas: a machine learning-based histogram analysis on conventional T2-weighted MRI. Neuroradiology. 2019;61(7):767-774. doi:10.1007/s00234-019-02211-2

23. Tjörnstrand A, Casar-Borota O, Heurling $\mathrm{K}$, et al. Lower 68 Ga-DOTATOC uptake in nonfunctioning pituitary neuroendocrine tumours compared to normal pituitary gland-A proof-of-concept study. Clin 
Endocrinol (Oxf). December 2019. doi:10.1111/cen.14144

24. Zhao X, Xiao J, Xing B, Wang R, Zhu Z, Li F. Comparison of (68)Ga DOTATATE to 18F-FDG uptake is useful in the differentiation of residual or recurrent pituitary adenoma from the remaining pituitary tissue after transsphenoidal adenomectomy. Clin Nucl Med. 2014;39(7):605-608. doi:10.1097/RLU.0000000000000457

25. Wang H, Hou B, Lu L, et al. PET/MRI in the Diagnosis of Hormone-Producing Pituitary Microadenoma: A Prospective Pilot Study. J Nucl Med. 2018;59(3):523-528. doi:10.2967/jnumed.117.191916

26. Xiao J, Zhu Z, Zhong D, Ma W, Wang R. Improvement in Diagnosis of Metastatic Pituitary Carcinoma by $68 \mathrm{Ga}$ DOTATATE PET/CT. Clin Nucl Med. 2015;40(2):e129-e131. doi:10.1097/RLU.0000000000000462

27. Garmes HM, Carvalheira JBC, Reis F, et al. Pituitary carcinoma: A case report and discussion of potential value of combined use of Ga-68 DOTATATE and F-18 FDG PET/CT scan to better choose therapy. Surg Neurol Int. 2017;8:162. doi:10.4103/sni.sni_498_16

28. Ferone D, Pivonello R, Lastoria S, et al. In vivo and in vitro effects of octreotide, quinagolide and cabergoline in four hyperprolactinaemic acromegalics: correlation with somatostatin and dopamine D2 $\begin{array}{lllll}\text { receptor } & \text { scintigraphy. } & \text { Clin } & \text { Endocrinol } & \text { 2001;54(4):469-477. }\end{array}$ http://www.ncbi.nlm.nih.gov/pubmed/11318782.

29. Muhr C. Positron Emission Tomography in Acromegaly and Other Pituitary Adenoma Patients. Neuroendocrinology. 2006;83(3-4):205-210. doi:10.1159/000095529

30. Bergström M, Muhr C, Lundberg PO, Långström B. PET as a tool in the clinical evaluation of pituitary adenomas. $J$ Nucl Med. 1991;32(4):610-615. http://www.ncbi.nlm.nih.gov/pubmed/2013801.

31. Jeong SY, Lee S-W, Lee HJ, et al. Incidental pituitary uptake on whole-body 18 F-FDG PET/CT: a multicentre study. Eur J Nucl Med Mol Imaging. 2010;37(12):2334-2343. doi:10.1007/s00259-010-15715

32. Hyun SH, Choi JY, Lee K-H, Choe YS, Kim B-T. Incidental Focal 18F-FDG Uptake in the Pituitary Gland: Clinical Significance and Differential Diagnostic Criteria. J Nucl Med. 2011;52(4):547-550. doi:10.2967/jnumed.110.083733

33. Maffei P, Marzola MC, Musto A, et al. A Very Rare Case of Nonfunctioning Pituitary Adenoma Incidentally Disclosed at 18F-FDG PET/CT. Clin Nucl Med. 2012;37(5):e100-e101. doi:10.1097/RLU.0b013e3182485217

34. Campeau RJ, David O, Dowling AM. Pituitary Adenoma Detected on FDG Positron Emission 
Tomography in a Patient with Mucosa-Associated Lymphoid Tissue Lymphoma. Clin Nucl Med. 2003;28(4):296-298. doi:10.1097/01.RLU.0000057554.55930.05

35. Karapolat İ, Öncel G, Kumanlığlu K. Clinically Occult Pituitary Adenoma Can Appear as a Hypermetabolic Lesion on Whole Body FDG PET Imaging in a Patient with Lymphoma. Malecular Imaging Radionucl Ther. 2013;22(1):18-20. doi:10.4274/Mirt.258

36. Gemmel F, Balink H, Collins J, Oomen P. Occult Prolactinoma Diagnosed by FDG PET/CT. Clin Nucl Med. 2010;35(4):269-270. doi:10.1097/RLU.0b013e3181d19098

37. Joshi P, Lele V, Gandhi R. Incidental detection of clinically occult follicle stimulating hormone secreting pituitary adenoma on whole body 18-Fluorodeoxyglucose positron emission tomography-computed tomography. Indian J Nucl Med. 2011;26(1):34-35. doi:10.4103/0972-3919.84611

38. Koo CW, Bhargava P, Rajagopalan V, Ghesani M, Sims-Childs H, Kagetsu NJ. Incidental detection of clinically occult pituitary adenoma on whole-body $\{\mathrm{FDG}\}\{\mathrm{PET}\}$ imaging. Clin Nucl Med. 2006;31(1):42-43.

39. Maiza J-C, Zunic P, Revel C, Schneebeli S. Acromegaly revealed by 18FDG-PET/CT in a plasmocytoma patient. Pituitary. 2012;15(4):614-615. doi:10.1007/s11102-012-0438-0

40. Komori T, Martin WH, Graber AL, Delbeke D. Serendipitous detection of \{Cushing\}'s disease by $\{F D G\}$ positron emission tomography and a review of the literature. Clin Nucl Med. 2002;27(3):176-178.

41. Seok H, Lee EJY, Choe EY, et al. Analysis of $18 \mathrm{~F}$-fluorodeoxyglucose positron emission tomography findings in patients with pituitary lesions. Korean $J$ Intern Med. 2013;28(1):81-88. doi:10.3904/kjim.2013.28.1.81

42. Alzahrani AS, Farhat R, Al-Arifi A, Al-Kahtani N, Kanaan I, Abouzied M. The diagnostic value of fused positron emission tomography/computed tomography in the localization of adrenocorticotropin-secreting pituitary adenoma in Cushing's disease. Pituitary. 2009;12(4):309-314. doi:10.1007/s11102-009-0180-4

43. Chittiboina P, Montgomery BK, Millo C, Herscovitch P, Lonser RR. High-resolution18Ffluorodeoxyglucose positron emission tomography and magnetic resonance imaging for pituitary adenoma detection in \{Cushing\} disease. J Neurosurg. 2015;122(4):791-797.

44. Boyle J, Patronas NJ, Smirniotopoulos J, et al. CRH stimulation improves 18F-FDG-PET detection of pituitary adenomas in Cushing's disease. Endocrine. 2019;65(1):155-165. doi:10.1007/s12020-01901944-7

45. Xiangsong Z, Dianchao Y, Anwu T. Dynamic 13N-ammonia $\{\mathrm{PET}\}$ : a new imaging method to diagnose hypopituitarism. J Nucl Med. 2005;46(1):44-47. 
46. Wang Z, Mao Z, Zhang X, et al. Utility of $13 \mathrm{~N}-$ Ammonia PET/CT to Detect Pituitary Tissue in Patients with Pituitary Adenomas. Acad Radiol. 2019;26(9):1222-1228. doi:10.1016/j.acra.2018.09.015

47. Haroon A, Zanoni L, Celli M, et al. Multicenter study evaluating extraprostatic uptake of 11C-choline, 18F-methylcholine, and 18F-ethylcholine in male patients: physiological distribution, statistical differences, imaging pearls, and normal variants. Nucl Med Commun. 2015;36(11). https://journals.lww.com/nuclearmedicinecomm/Fulltext/2015/11000/Multicenter_study_evaluating_ext raprostatic_uptake.1.aspx.

48. Schillaci O, Calabria F, Tavolozza M, et al. 18F-choline PET/CT physiological distribution and pitfalls in image interpretation: experience in 80 patients with prostate cancer. Nucl Med Commun. 2010;31(1):39-45. doi:10.1097/MNM.0b013e328330adc5

49. Maffione AM, Mandoliti G, Pasini F, Colletti PM, Rubello D. Pituitary Non-Functioning Adenoma Disclosed at 18F-Choline PET/CT to Investigate a Prostate Cancer Relapse. Clin Nucl Med. 2016;41(10):e460-e461. doi:10.1097/RLU.0000000000001328

50. Albano D, Bosio G, Bertagna F. Incidental pituitary adenoma detected by 18 F-FDG PET/CT and 18 Fcholine PET/CT in the same patient. Rev Esp Med Nucl Imagen Mol. 2018;37(4):250-252. doi:10.1016/j.remn.2017.07.002

51. Hiel B van der, Stokkel MPM, Buikhuisen WA, et al. 18F-Choline PET/CT as a New Tool for Functional Imaging of Non-Proliferating Secreting Neuroendocrine Tumors. J Endocrinol Metab. 2015;5(4):267271. doi:10.14740/JEM.V5I4.300

52. Feng Z, He D, Mao Z, et al. Utility of 11C-Methionine and 18F-FDG PET/CT in Patients With Functioning Pituitary Adenomas. Clin Nucl Med. 2016;41(3):e130-e134. doi:10.1097/RLU.0000000000001085

53. Tomura N, Saginoya T, Mizuno Y, Goto H. Accumulation of 11 C-methionine in the normal pituitary gland on 11 C-methionine PET. Acta radiol. 2017;58(3):362-366. doi:10.1177/0284185116651005

54. Ikeda H, Abe T, Watanabe K. Usefulness of composite methionine-positron emission tomography/3.0tesla magnetic resonance imaging to detect the localization and extent of early-stage Cushing adenoma. $J$ Neurosurg. 2010;112(4):750-755. doi:10.3171/2009.7.JNS09285

55. Rodriguez-Barcelo S, Gutierrez-Cardo A, Dominguez-Paez M, Medina-Imbroda J, Romero-Moreno L, Arraez-Sanchez M. Clinical Usefulness of Coregistered 11C-Methionine Positron Emission Tomography/3-T Magnetic Resonance Imaging at the Follow-Up of Acromegaly. World Neurosurg. 2014;82(3-4):468-473. doi:10.1016/j.wneu.2013.11.011

56. Koulouri O, Steuwe A, Gillett D, et al. A role for 11C-methionine PET imaging in ACTH-dependent 
Cushing’s syndrome. Eur J Endocrinol. 2015;173(4):M107-20. doi:10.1530/EJE-15-0616

57. Koulouri O, Steuwe A, Gillett D, et al. A role for 11C-methionine PET imaging in ACTH-dependent Cushing's syndrome. Eur J Endocrinol. 2015;173(4):M107-M120. doi:10.1530/EJE-15-0616

58. Koulouri O, Hoole AC, English P, et al. Localisation of an occult thyrotropinoma with $11 \mathrm{C}$-methionine PET-CT before and after somatostatin analogue therapy. Lancet Diabetes Endocrinol. 2016;4(12):1050. doi:10.1016/S2213-8587(16)30311-4

59. Potorac I, Beckers A, Bonneville J-F. T2-weighted MRI signal intensity as a predictor of hormonal and tumoral responses to somatostatin receptor ligands in acromegaly: a perspective. Pituitary. 2017;20(1):116-120. doi:10.1007/s11102-017-0788-8

60. Heck A, Emblem KE, Casar-Borota O, Bollerslev J, Ringstad G. Quantitative analyses of T2-weighted MRI as a potential marker for response to somatostatin analogs in newly diagnosed acromegaly. Endocrine. 2016;52(2):333-343. doi:10.1007/s12020-015-0766-8

61. Varlamov E V., Hinojosa-Amaya JM, Fleseriu M. Magnetic resonance imaging in the management of prolactinomas; a review of the evidence. Pituitary. 2020;23(1):16-26. doi:10.1007/s11102-019-01001-6

62. Cazabat L, Dupuy M, Boulin A, et al. Silent, but not unseen: multimicrocystic aspect on T2-weighted MRI in silent corticotroph adenomas. Clin Endocrinol (Oxf). 2014;81(4):566-572. doi:10.1111/cen.12443

63. Chernov MF, Kawamata T, Amano K, et al. Possible role of single-voxel 1H-MRS in differential diagnosis of suprasellar tumors. J Neurooncol. 2009;91(2):191-198. doi:10.1007/s11060-008-9698-y

64. Pînzariu O, Georgescu B, Georgescu CE. Metabolomics-A Promising Approach to Pituitary Adenomas. Front Endocrinol (Lausanne). 2019;9:814. doi:10.3389/fendo.2018.00814

65. Hainc N, Stippich C, Reinhardt J, et al. Golden-angle radial sparse parallel (GRASP) MRI in clinical routine detection of pituitary microadenomas: First experience and feasibility. Magn Reson Imaging. 2019;60:38-43. doi:10.1016/j.mri.2019.03.015

66. Manara R, Maffei P, Citton V, et al. Increased Rate of Intracranial Saccular Aneurysms in Acromegaly: An MR Angiography Study and Review of the Literature. J Clin Endocrinol Metab. 2011;96(5):12921300. doi:10.1210/jc.2010-2721

67. Hakyemez B, Yildirim N, Erdoðan C, Kocaeli H, Korfali E, Parlak M. Meningiomas with conventional MRI findings resembling intraaxial tumors: can perfusion-weighted MRI be helpful in differentiation? Neuroradiology. 2006;48(10):695-702. doi:10.1007/s00234-006-0115-y

68. Bladowska J, Zimny A, Guziński M, et al. Usefulness of perfusion weighted magnetic resonance imaging 
with signal-intensity curves analysis in the differential diagnosis of sellar and parasellar tumors: Preliminary report. Eur J Radiol. 2013;82(8):1292-1298. doi:10.1016/j.ejrad.2013.01.033

69. Rogg JM, Tung GA, Anderson G, Cortez S. Pituitary apoplexy: early detection with diffusion-weighted MR imaging. AJNR Am $J \quad$ Neuroradiol. 2002;23(7):1240-1245. http://www.ncbi.nlm.nih.gov/pubmed/12169486. Accessed April 23, 2019.

70. Kunii N, Abe T, Kawamo M, Tanioka D, Izumiyama H, Moritani T. Rathke's cleft cysts: differentiation from other cystic lesions in the pituitary fossa by use of single-shot fast spin-echo diffusion-weighted MR imaging. Acta Neurochir (Wien). 2007;149(8):759-769. doi:10.1007/s00701-007-1234-x

71. de Rotte AAJ, Groenewegen A, Rutgers DR, et al. High resolution pituitary gland MRI at 7.0 tesla: a clinical evaluation in Cushing's disease. Eur Radiol. 2016;26(1):271-277. doi:10.1007/s00330-015-3809$\mathrm{x}$

72. Patel V, Liu CSJ, Shiroishi MS, et al. Ultra-high field magnetic resonance imaging for localization of corticotropin-secreting pituitary adenomas. Neuroradiology. 2020. doi:10.1007/s00234-020-02431-x

73. Chatain GP, Patronas N, Smirniotopoulos JG, et al. Potential utility of FLAIR in MRI-negative Cushing's disease. J Neurosurg. 2018;129(3):620-628. doi:10.3171/2017.4.JNS17234

74. Lang M, Habboub G, Moon D, et al. Comparison of Constructive Interference in Steady-State and T1Weighted MRI Sequence at Detecting Pituitary Adenomas in Cushing's Disease Patients. J Neurol Surg Part B Skull Base. 2018;79(06):593-598. doi:10.1055/s-0038-1642032

75. Yamamoto J, Kakeda S, Shimajiri S, et al. Tumor consistency of pituitary macroadenomas: Predictive analysis on the basis of imaging features with contrast-enhanced 3D FIESTA at 3T. Am J Neuroradiol. 2014;35(2):297-303. doi:10.3174/ajnr.A3667

76. Hughes JD, Fattahi N, Van Gompel J, Arani A, Ehman R, Huston J. Magnetic resonance elastography detects tumoral consistency in pituitary macroadenomas. Pituitary. 2016;19(3):286-292. doi:10.1007/s11102-016-0706-5

77. Pierallini A, Caramia F, Falcone C, et al. Pituitary Macroadenomas: Preoperative Evaluation of Consistency with Diffusion-weighted MR Imaging_-Initial Experience. Radiology. 2006;239(1):223231. doi:10.1148/radiol.2383042204

78. Suzuki C, Maeda M, Hori K, et al. Apparent diffusion coefficient of pituitary macroadenoma evaluated with line-scan diffusion-weighted imaging. $J$ Neuroradiol. 2007;34(4):228-235. doi:10.1016/j.neurad.2007.06.007

79. Mahmoud OM, Tominaga A, Amatya VJ, et al. Role of PROPELLER diffusion-weighted imaging and 
apparent diffusion coefficient in the evaluation of pituitary adenomas. Eur J Radiol. 2011;80(2):412-417. doi:10.1016/j.ejrad.2010.05.023

80. Alimohamadi M, Sanjari R, Mortazavi A, et al. Predictive value of diffusion-weighted MRI for tumor consistency and resection rate of nonfunctional pituitary macroadenomas. Acta Neurochir (Wien). 2014;156(12):2245-2252. doi:10.1007/s00701-014-2259-6

81. Yiping L, Ji X, Daoying G, Bo Y. Prediction of the consistency of pituitary adenoma: A comparative study on diffusion-weighted imaging and pathological results. J Neuroradiol. 2016;43(3):186-194. doi:10.1016/j.neurad.2015.09.003

82. Wang M, Liu H, Wei X, et al. Application of Reduced-FOV Diffusion-Weighted Imaging in Evaluation of Normal Pituitary Glands and Pituitary Macroadenomas. AJNR Am J Neuroradiol. 2018;39(8):14991504. doi:10.3174/ajnr.A5735

83. Sanei Taheri M, Kimia F, Mehrnahad M, et al. Accuracy of diffusion-weighted imaging-magnetic resonance in differentiating functional from non-functional pituitary macro-adenoma and classification of tumor consistency. Neuroradiol J. 2019;32(2):74-85. doi:10.1177/1971400918809825

84. Ma Z, He W, Zhao Y, et al. Predictive value of PWI for blood supply and T1-spin echo MRI for consistency of pituitary adenoma. Neuroradiology. 2016;58(1):51-57. doi:10.1007/s00234-015-1591-8

85. Linn J, Peters F, Lummel N, et al. Detailed imaging of the normal anatomy and pathologic conditions of the cavernous region at 3 Tesla using a contrast-enhanced MR angiography. Neuroradiology. 2011;53(12):947-954. doi:10.1007/s00234-011-0837-3

86. Micko ASG, Wöhrer A, Wolfsberger S, Knosp E. Invasion of the cavernous sinus space in pituitary adenomas: endoscopic verification and its correlation with an MRI-based classification. $J$ Neurosurg. 2015;122(4):803-811. doi:10.3171/2014.12.JNS141083

87. Watanabe K, Kakeda S, Yamamoto J, et al. Delineation of Optic Nerves and Chiasm in Close Proximity to Large Suprasellar Tumors with Contrast-enhanced FIESTA MR Imaging. Radiology. 2012;264(3):852858. doi:10.1148/radiol.12111363

88. Suprasanna K, Vinay Kumar KM, Kumar A, Mithra P. Comparison of pituitary stalk angle, inter-neural angle and optic tract angle in relation to optic chiasm location on 3-dimensional magnetic resonance imaging. J Clin Neurosci. 2019;64:169-173. doi:10.1016/j.jocn.2019.03.010

89. Yu CS, Li KC, Xuan Y, Ji XM, Qin W. Diffusion tensor tractography in patients with cerebral tumors: A helpful technique for neurosurgical planning and postoperative assessment. Eur J Radiol. 2005;56(2):197204. doi:10.1016/j.ejrad.2005.04.010 
90. Salmela MB, Cauley KA, Nickerson JP, Koski CJ, Filippi CG. Magnetic resonance diffusion tensor imaging (MRDTI) and tractography in children with septo-optic dysplasia. Pediatr Radiol. 2010;40(5):708-713. doi:10.1007/s00247-009-1478-0

91. Anik I, Anik Y, Cabuk B, et al. Visual Outcome of an Endoscopic Endonasal Transsphenoidal Approach in Pituitary Macroadenomas: Quantitative Assessment with Diffusion Tensor Imaging Early and LongTerm Results. World Neurosurg. 2018;112:e691-e701. doi:10.1016/j.wneu.2018.01.134

92. Hu J, Yan J, Zheng X, et al. Magnetic resonance spectroscopy may serve as a presurgical predictor of somatostatin analog therapy response in patients with growth hormone-secreting pituitary macroadenomas. J Endocrinol Invest. 2019;42(4):443-451. doi:10.1007/s40618-018-0939-4

93. Hassan HA, Bessar MA, Herzallah IR, Laury AM, Arnaout MM, Basha MAA. Diagnostic value of early postoperative MRI and diffusion-weighted imaging following trans-sphenoidal resection of nonfunctioning pituitary macroadenomas. Clin Radiol. 2018;73(6):535-541. doi:10.1016/j.crad.2017.12.007 


\begin{tabular}{|c|c|c|}
\hline $\begin{array}{l}\text { T2-WEIGHTED MRI } \\
\text { APPEARANCE }\end{array}$ & DIFFERENTIAL DIAGNOSIS & References \\
\hline Hypointense & $\begin{array}{l}\text { Rathke's cleft cyst } \\
\text { Hypointensity observed in one third of cases, although hypointense } \\
\text { intracystic nodules are present in up to } 70 \% \text { of cases which are virually } \\
\text { pathognomonic. } \\
\text { GH-secreting PA (>50\%) } \\
\text { Hypointensity typically associated with: } \\
\text { - Smaller tumours } \\
\text { - Lower tendency to CSI } \\
\text { - Greater SSA responsiveness } \\
\text { Prolactinoma } \\
\text { Hypointensity seen in a subset of cases (up to 20\%, especially in men); } \\
\text { unclear whether this predicts resistance to DA therapy; may indicate } \\
\text { greater likelihood of growth during pregnancy }\end{array}$ & $20,59,60$ \\
\hline $\begin{array}{l}\text { Hyperintense } \\
\text { (often strongly) }\end{array}$ & $\begin{array}{l}\text { Hypophysitis } \\
\text { E.g. Iymphocytic/autoimmune, immunotherapy-related or IgG-4 } \\
\text { disease }\end{array}$ & 20 \\
\hline Hyperintense & $\begin{array}{l}\text { Rathke's cleft cyst } \\
\text { Hyperintensity observed in } 70 \% \text { of cases. }\end{array}$ & 20 \\
\hline $\begin{array}{l}\text { Hyperintense } \\
\text { (mild-moderate) }\end{array}$ & $\begin{array}{l}\text { Prolactinoma (especially microadenomas) } \\
\text { In general, degree of hyperintensity does not reliably predict response } \\
\text { to DA therapy; accentuation of hyperintensity may occur following DA } \\
\text { therapy }\end{array}$ & 61 \\
\hline $\begin{array}{l}\text { Hyperintense/ } \\
\text { isointense }\end{array}$ & $\begin{array}{l}\text { GH-secreting PA: } \\
\text { Hyperintensity/isointensity associated with: } \\
\text { larger tumours } \\
\text { greater tendency to CSI } \\
\text { less SSA responsiveness }\end{array}$ & $20,59,60$ \\
\hline Microcystic pattern & $\begin{array}{l}\text { Silent corticotroph (macro)adenoma (SCA) } \\
\text { Multiple microcysts (small areas of high-intensity signal covering at } \\
\text { least } 25 \% \text { of the tumour) observed in } 50-75 \% \text { of cases }\end{array}$ & $20,,^{62}$ \\
\hline
\end{tabular}

Key: CSI, cavernous sinus invasion; DA, dopamine agonist; GH, growth hormone; IgG-4, immunoglobulin subtype-4; MRI, magnetic resonance imaging; PA, pituitary adenoma; SSA, somatostatin analogue therapy. 
TABle 2. Alternative MR Sequences/TECHNIQUES For PITUITARy IMAGING

\begin{tabular}{|c|c|c|}
\hline INDICATIONS & MR SEQUENCE/TECHNIQUE & References \\
\hline \multicolumn{3}{|l|}{ A: Aid to diagnosis } \\
\hline $\begin{array}{l}\text { Distinguish normal pituitary } \\
\text { gland from PA or cyst }\end{array}$ & $\begin{array}{l}\text { Magnetic resonance spectroscopy (MRS) } \\
\text { Golden-angle radial sparse parallel MRI (GRASP) }\end{array}$ & $63-65$ \\
\hline \multirow{2}{*}{$\begin{array}{l}\text { Distinguish PA from vascular } \\
\text { lesions (e.g. aneurysm, } \\
\text { meningioma) }\end{array}$} & Magnetic resonance angiography (MRA) & 66 \\
\hline & Perfusion weighted imaging (PWI) & 67,68 \\
\hline $\begin{array}{l}\text { Detection of apoplexy and } \\
\text { cystic lesions }\end{array}$ & Diffusion weighted imaging (DWI) & 69,70 \\
\hline $\begin{array}{l}\text { Localisation of corticotroph } \\
\text { tumours }\end{array}$ & $\begin{array}{l}\text { 7T (ultra-high field) MRI } \\
\text { Fluid Attenuation Inversion Recovery (FLAIR) } \\
\text { Constructive interference in steady state (CISS*) }\end{array}$ & $71-74$ \\
\hline \multicolumn{3}{|l|}{ B: Preoperative assessment } \\
\hline $\begin{array}{l}\text { Assessment of tumour } \\
\text { consistency }\end{array}$ & $\begin{array}{l}\text { Contrast-enhanced Fast Imaging Employing Steady-state } \\
\text { Acquisition (FIESTA) } \\
\text { Magnetic resonance elastography (MRE) } \\
\text { Apparent diffusion coefficient (ADC - a subtype of DWI) }\end{array}$ & $\begin{array}{c}75 \\
76 \\
77-83\end{array}$ \\
\hline $\begin{array}{l}\text { Assessment of tumour } \\
\text { vascularity }\end{array}$ & Perfusion weighted imaging (PWI) & 84 \\
\hline $\begin{array}{l}\text { Delineation of cavernous sinus } \\
\text { structures / tumour invasion }\end{array}$ & Magnetic resonance angiography (MRA) & 85,86 \\
\hline $\begin{array}{l}\text { Delineation of visual pathways } \\
\text { (including optic nerve } \\
\text { tractography) }\end{array}$ & $\begin{array}{l}\text { Contrast-enhanced Fast Imaging Employing Steady-state } \\
\text { Acquisition (FIESTA) } \\
\text { 3D-constructive interference in steady state (CISS*) } \\
\text { Diffusion tensor imaging (DTI - an extension of DWI) }\end{array}$ & $\begin{array}{c}87 \\
88 \\
89-91\end{array}$ \\
\hline \multicolumn{3}{|l|}{ C: Prediction of treatment outcome } \\
\hline Response to SSA therapy & Magnetic resonance spectroscopy (MRS) & 92 \\
\hline $\begin{array}{l}\text { Visual outcomes following } \\
\text { pituitary surgery }\end{array}$ & Diffusion tensor imaging (DTI) & 91 \\
\hline $\begin{array}{l}\text { Successful tumour resection at } \\
\text { TSS }\end{array}$ & Apparent diffusion coefficient (ADC - a subtype of DWI) & 80,93 \\
\hline
\end{tabular}

Key: 7T, 7 Tesla; MRI, magnetic resonance imaging; SSA, somatostatin analogue therapy; TSS, transsphenoidal surgery; ${ }^{*} \mathrm{CISS}$ denotes a T2 gradient echo sequence 


\section{Figure legends}

Fig 1. Prediction of pituitary tumour phenotype based on T2-weighted MRI appearances. A-C, T1 SE (pre- and post-contrast) and T2 FSE MRI in a patient with acromegaly, demonstrating a rightsided macroadenoma; the tumour is hypointense on T2 sequences when compared to the adjacent temporal lobe, which has been linked with somatostain analogue responsiveness and a densely granulated appearance on histology. D-I, T1 SE (pre- and post-contrast) and T2W FSE MRI showing a macroadenoma with suprasellar extension in a patient who presented with visual loss, but no clinical or biochemical features of hypercortisolism; the tumour exhibits multiple microcysts (focal small areas of high intensity) on the T2 images. Key: FSE, Fast Spin Echo; Gad, gadolinium; SE, Spin Echo; T1, T1weighted; T2, T2-weighted.

Fig 2. Identification of the site of an occult microadenoma in Cushing's Disease. A-B, T1 SE MRI is unable to identify a discrete adenoma. C-D. Volumetric (FSPGR) MRI is also equivocal, but raises the possibility of a subtle area of hypoattenuation in the left side of the gland (yellow arrow). E-F, Met$\mathrm{PET} / \mathrm{MR}^{\mathrm{CR}}$ demonstrates focal increased tracer uptake (yellow arrow) corresponding to the area seen on volumetric MRI (and subsequently confirmed at transsphenoidal surgery); normal physiological tracer uptake is seen in the right side of the gland (white arrow). Key: FSPGR, Fast Spoiled Gradient Recalled Echo; Gad, gadolinium; Met-PET/MR ${ }^{\mathrm{CR}},{ }^{11} \mathrm{C}$-methionine PET/CT coregistered with FSPGR MRI; SE, Spin Echo; T1, T1-weighted.

Fig 3. Identification of the site of an occult microadenoma in acromegaly. A-B, T1 SE MRI demonstrates equivocal findings with no discrete adenoma visualised. C-D, Volumetric (FSPGR) MRI identifies a $5 \mathrm{~mm}$ focal hypointensity in the right inferior aspect of the gland (yellow arrow) suggestive of a microadenoma. E-F, Met-PET/MR ${ }^{C R}$ reveals an area of focal high tracer uptake (yellow arrow) at the site of the suspected microadenoma. Key: FSPGR, Fast Spoiled Gradient Recalled Echo; Gad, gadolinium; Met-PET/MR ${ }^{C R},{ }^{11} \mathrm{C}$-methionine PET/CT coregistered with FSPGR MRI; SE, Spin Echo; T1, T1-weighted.

Fig 4. Localisation of the site of early recurrence (at 8 months) following primary surgery in a patient with acromegaly (sparsely granulated tumour; MIB-1 proliferation index $=15 \%$ ). A-B, T1SE MRI shows a largely empty sella, but with a possible area of abnormal tissue posterior to the site of insertion of the infundibulum (yellow arrow). C-D. Volumetric (FSPGR) MRI demonstrates a similar appearance. E-F, Met-PET/MR ${ }^{C R}$ shows focal high tracer uptake at the suspected site of recurrence (confirmed at repeat transsphenoidal surgery). Key: FSPGR, Fast Spoiled Gradient Recalled Echo; 
Gad, gadolinium; Met-PET/MR ${ }^{C R},{ }^{11} \mathrm{C}$-methionine PET/CT coregistered with FSPGR MRI; SE, Spin Echo; T1, T1-weighted.

Fig 5. Localisation of the site of late recurrence (at 48 months) following primary surgery in a patient with Cushing's Disease. A-B. T1-SE MRI demonstrates an area of hypointensity adjacent to (yellow arrow), and possibly invading (yellow dashed arrow), the left cavernous sinus. C-D. Volumetric (FSPGR) MRI suggests the area of abnormal signal lies medial to the cavernous sinus. E-F, Met$P E T / M R^{C R}$ shows focal high tracer uptake that corresponds with the findings of FSPGR MRI (confirmed at repeat transsphenoidal surgery with complete postoperative biochemical remission); normal physiological tracer uptake is seen in the right side of the gland (white arrow). Key: FSPGR, Fast Spoiled Gradient Recalled Echo; Gad, gadolinium; Met-PET/MR ${ }^{C R},{ }^{11} \mathrm{C}$-methionine PET/CT coregistered with FSPGR MRI; SE, Spin Echo; T1, T1-weighted. 
Figure 1

Case 1

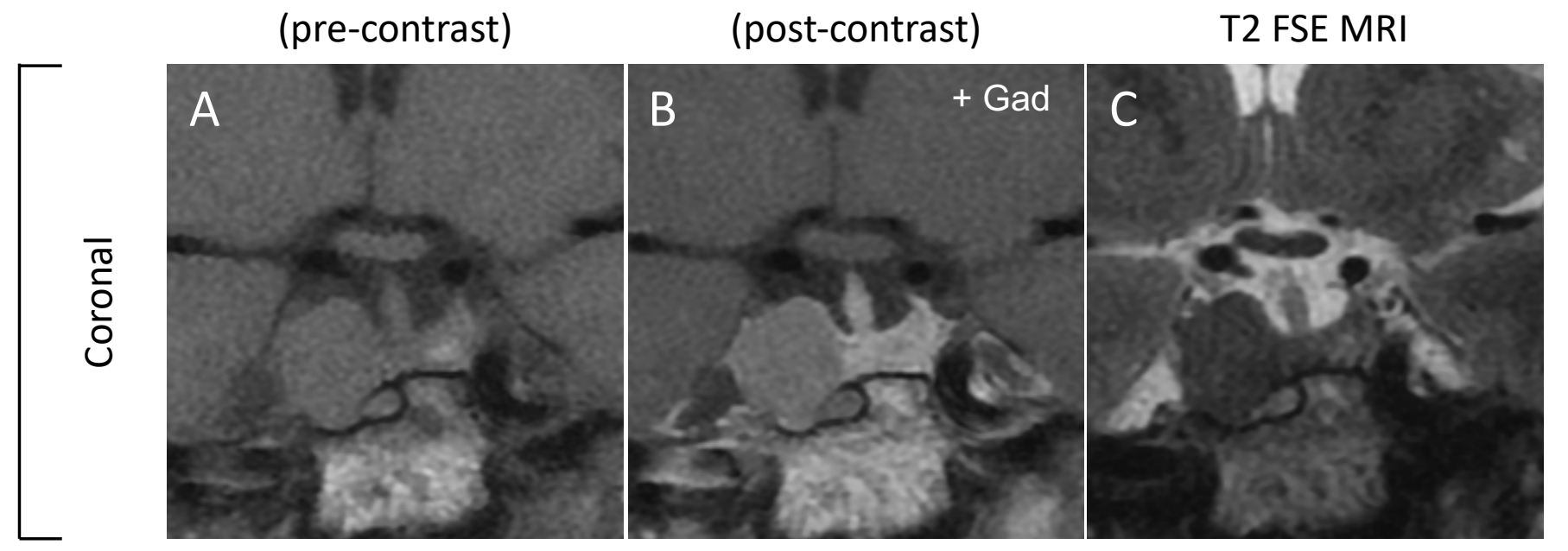

Case 2

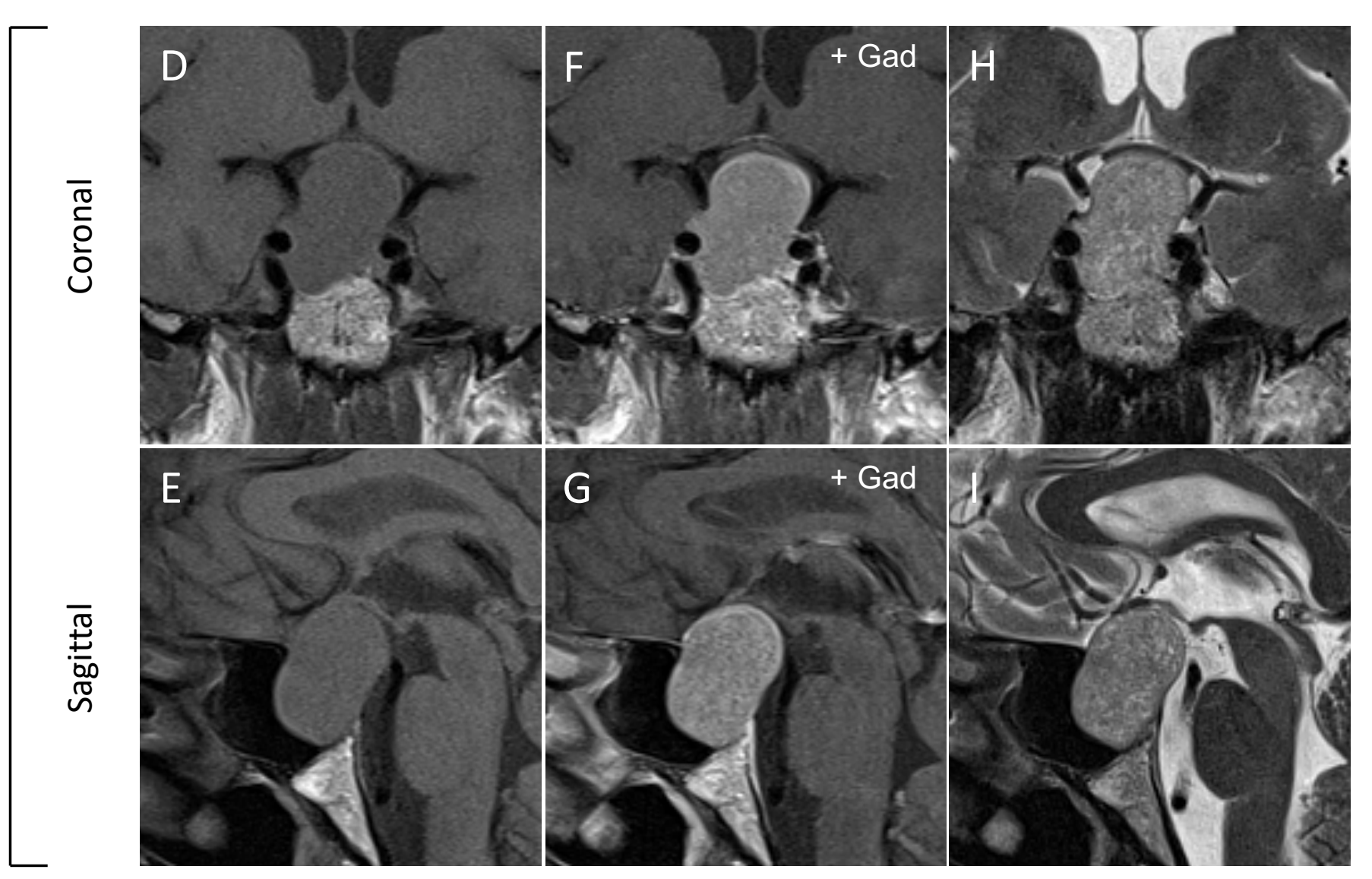


T1 SE MRI

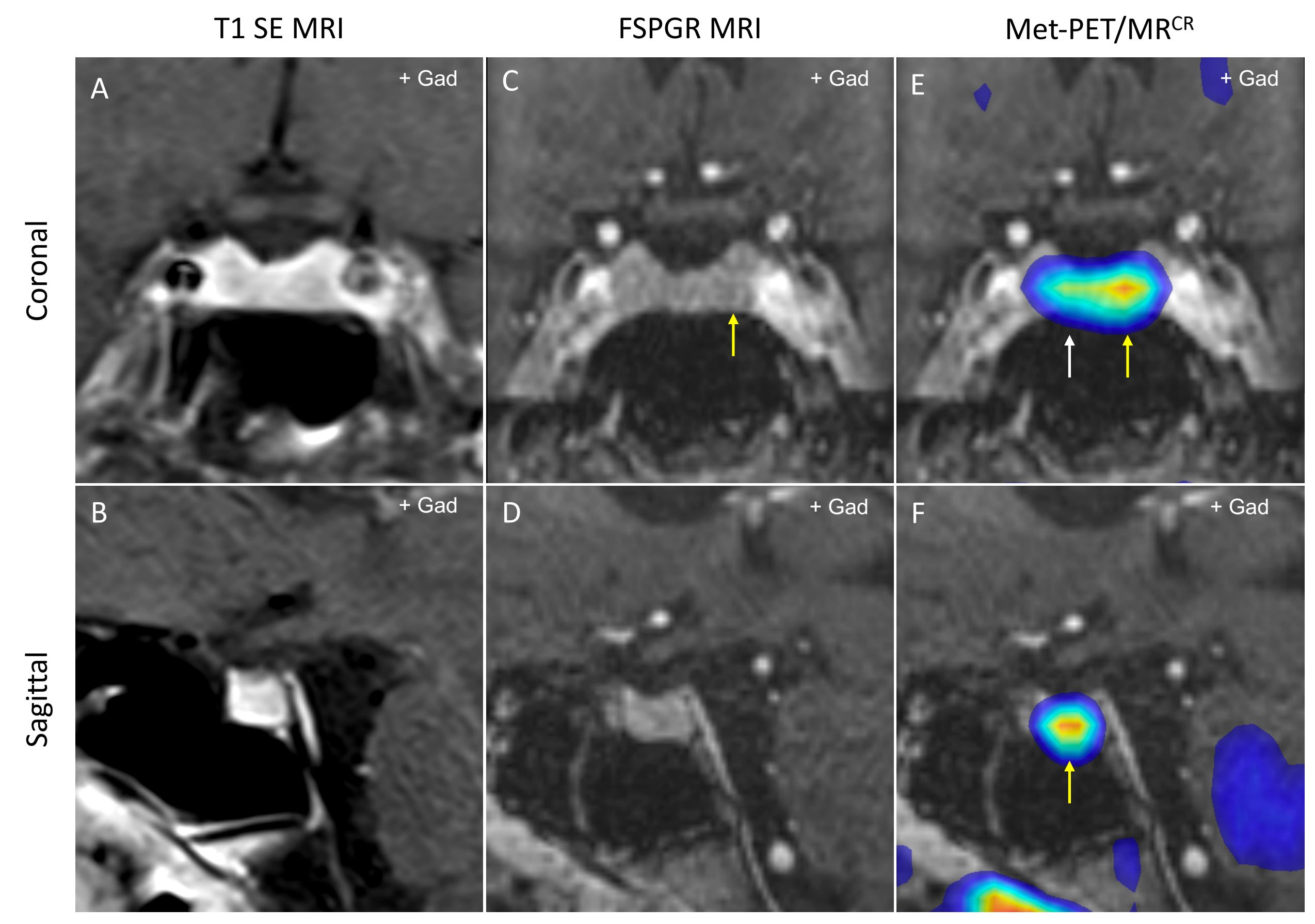

\section{Met-PET/MRCR}

Figure 2 


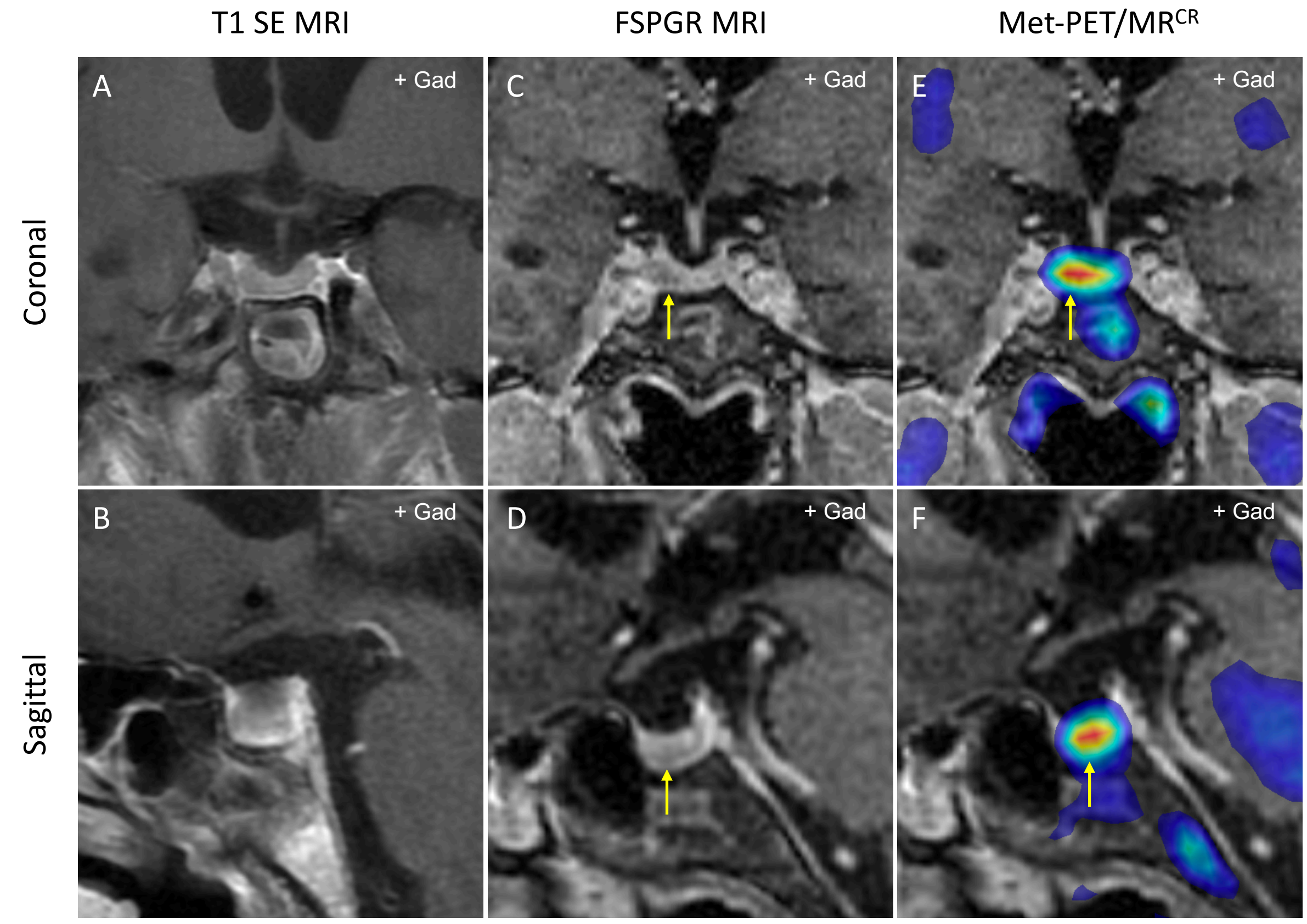


Figure 4

T1 SE MRI

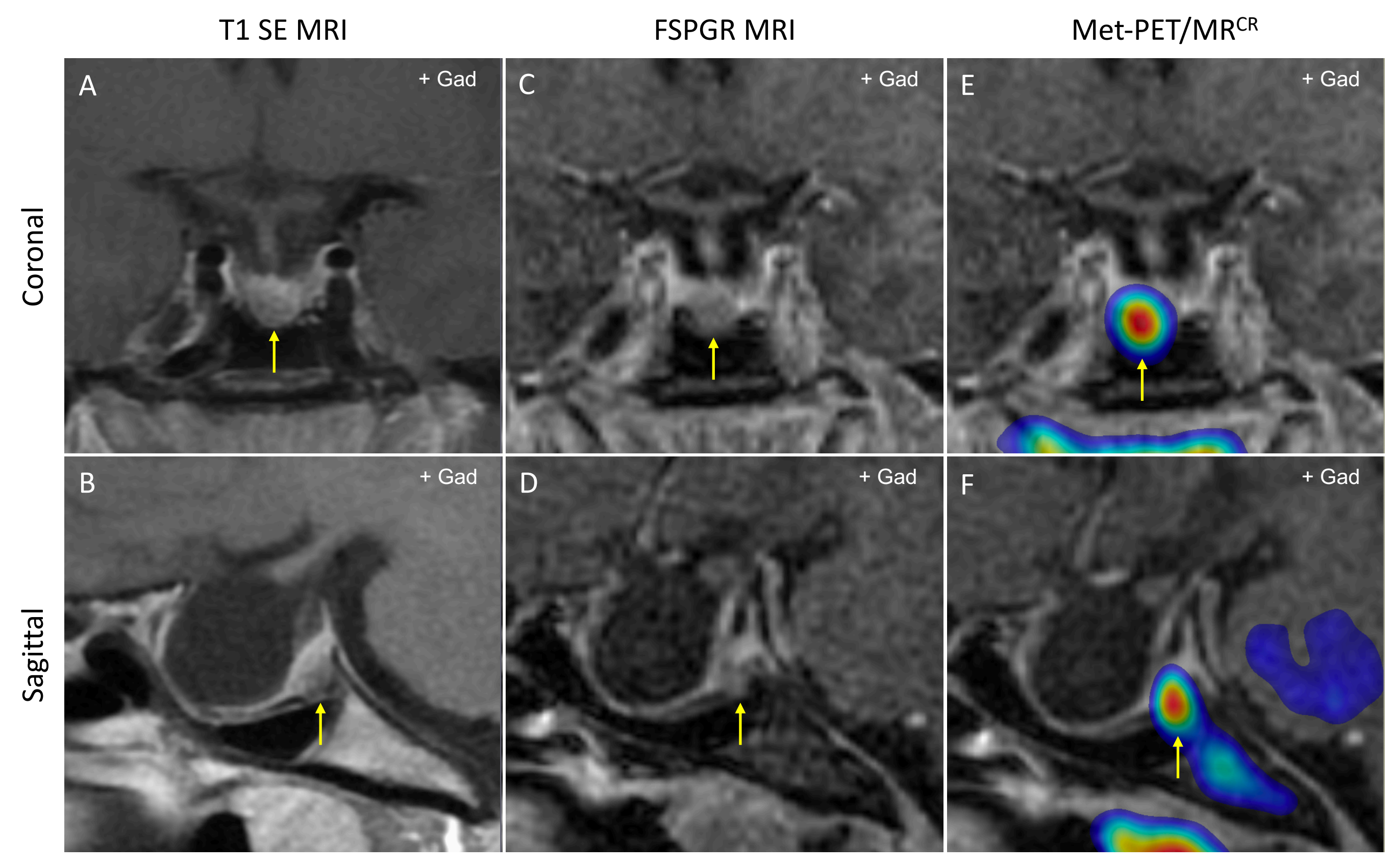

Met-PET/MRCR

FSPGR MRI 
Figure 5

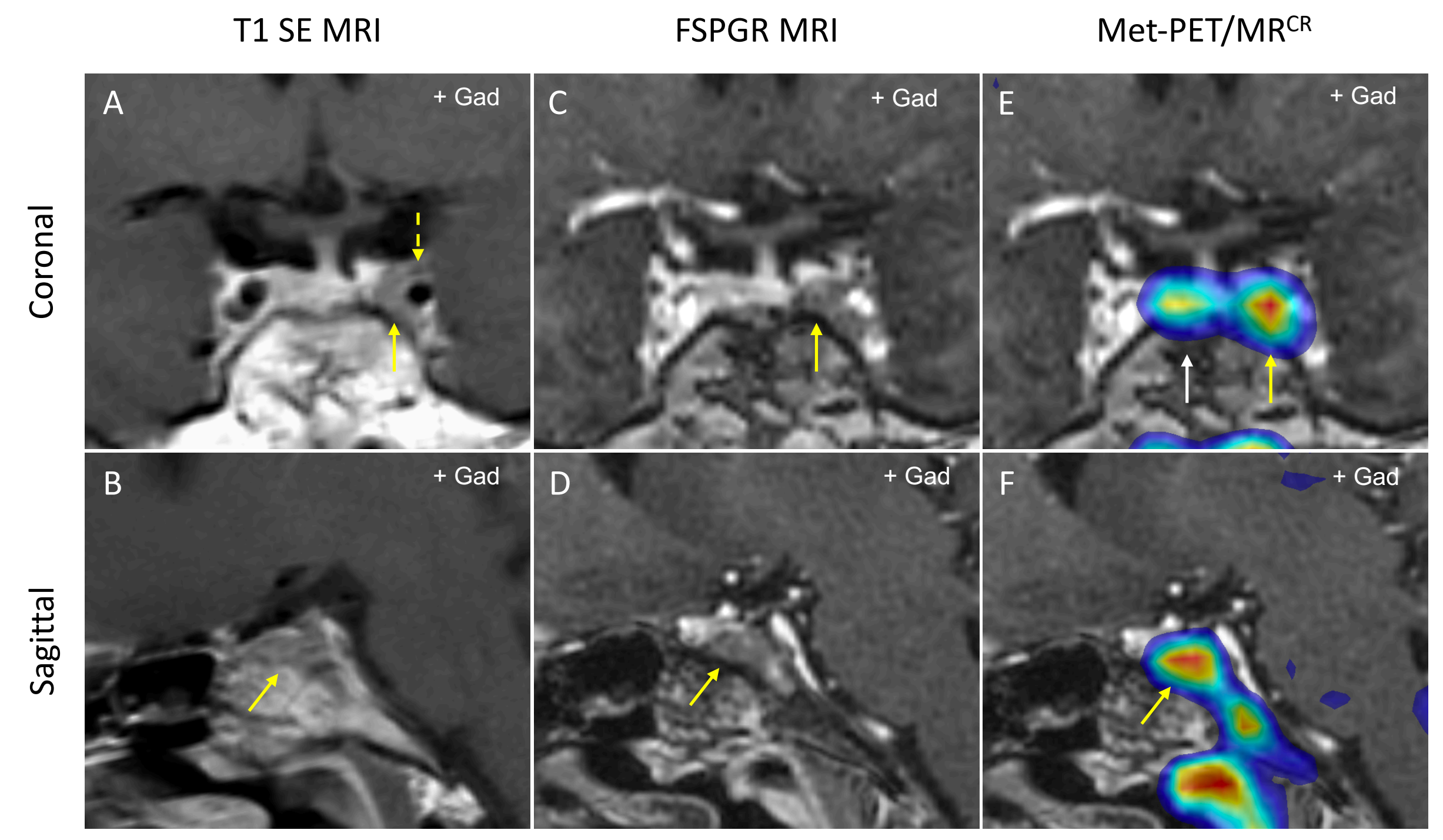

